\title{
The Connection between Teaching Methods - Alternative or Frontal - and Mathematics Achievements in Classrooms that Combine Computers in Learning and Teaching
}

\author{
Dina Hassidov \\ Talpiot College of Education \\ Israel
}

\begin{abstract}
A comparison of teaching methods in mathematics (frontal vs. computer enhanced and/or other alternative methods) in two urban elementary schools (479 students; grades 4-6; total 18 teachers) indicated that a significant difference in the achievement of the students resulted from the latter method, particularly for girls in the case of answering word problems. Follow-up studies corroborated the findings, indicating that the teaching method is a decisive factor in student achievement in math and that enhancing teaching with computer practice is of prime importance.
\end{abstract}

\section{Introduction}

Less than $60 \%$ of students in Israel achieve a passing mark in math in elementary school, and only a small percentage of high school students graduate with an understanding of science and math, despite recent technological developments in education [1]. This aligns with international data that shows a decline in math and science studies, especially in remote and underprivileged neighborhoods [1]. Children in underprivileged areas do not normally have access to appropriate (or state-of-the-art) educational resources, and teachers who teach in underprivileged areas often do not have proper training [2]. The lacuna of such children, who lack school preparation and are deficient in perception, speech, sorting, abstraction, reading, and conceptual abilities gradually increases with time, often resulting in failure to graduate.

The computer is highly regarded for its contribution to improving learning capacity, strengthening student confidence, and preparing them for the modern world [3, 4]. The gap between the underprivileged and the well-off is clearly denoted by computers. The former are much less likely to access computer-assisted learning: about $32 \%$ of students in affluent schools participate in computer-assisted learning, compared to only $17 \%$ of underprivileged students [5].

\section{Alternative Teaching Methods}

Alternative teaching methods stem from the point of view that diverse teaching methods can activate and engage students. Integrating technologies adapted to the different needs and levels of the heterogeneous classroom helps address psychological and epistemological aspects, serves as a basis for creating models for mathematics teaching, and takes into account the abilities and limitations of each child. Alternative teaching methods include encouraging discussion and dialogue by asking leading question and echoing students' ideas. Another is teaching in small groups, which allows more effective learning and flexible instruction based on the unique needs of the individuals in the group. Another alternative teaching method is use of the computer [6].

Harari shows that incorporating computers in teaching contributes to the learning process and recommends, inter alia, conducting "a comprehensive campaign to introduce the use of computers in all educational institutions at all levels and in all subjects" ([1], p. 7). Osin, Nesher and Ram note that "teaching mathematics in elementary schools using computers improves student achievement" ([7], p. 15). The use of computers for teaching math in elementary school allows visualization of mathematical problems, simplifying them for students.

In Israel, the math curriculum (grades 2 through 8) comprises a computerized program of study designed to evaluate and drill students. It presents exercises and word problems suited to the grade (or knowledge) level, checks performance, and progresses according to the results. The computer system provides the teacher with reports on progress and achievements for each student [8,9], thus revealing heterogeneity among students, even within one class (the levels of students in one class often span two to three years of study) and encouraging teachers to implement teaching methods tailored to the varying needs of students, not only in the computer room but also in the 
classroom. A group of teachers who taught math reported that computer-assisted teaching exposed them to the diversity among their students and encouraged them to find alternatives to the traditional frontal teaching method [10].

Mevarech and Rich [11] examined student achievement in math in schools in disadvantaged areas and found that students in grades 3 to 5 with similar socioeconomic backgrounds achieved more when they studied with computer assistance. Improvements were particularly high among fourthgraders who studied with computer assistance: their improvement showed a standard deviation of almost 1. Other studies (see for example, [12]) demonstrated similar results.

\section{The value of integrating computer systems}

Regarding the average annual progress of the students in math on the computer, a study carried out by the Ministry of Education (MoE) demonstrated that before introduction of computer systems in schools, the average annual progression was 3.5 computer levels per year (calculated as the difference between initial and final levels on the computer, assessed in accordance with the curriculum of the $\mathrm{MoE}$ ). After, the rates of progression (over the academic year) for weak, average, and strong students were 5.3, 9.5, and 13.7, respectively. In short, all students who studied the math curriculum aided by the computer progressed significantly during the year, but high achievers progressed the most [1].

Similarly, mathematics achievement levels before and after introduction of computers were tested among underprivileged populations. The study shows that improvement as reflected by the computer was almost double: $55 \%$ to $93 \%$.

Studies also indicate satisfaction among teachers, who see great potential in integrating computers into teaching, not the least of which are computer management of learning and the detailed reports a computer can provide which serve as a means of advancing students. Teachers noted the feedback provided by computer reports as a key tool for individually handling students and adapting teaching methods to their unique needs, and that the diagnostics of student performance allowed identification of learning problems, the opportunity for oral practice, and the increase in student motivation ultimately leading to the expansion of knowledge. One of the major shortcomings of the system that teachers indicated is that the program does not explain what the student's mistake is.

Most teachers are convinced that the computer contributes to teachers and students alike, and express satisfaction with the integration of computers in teaching. The study shows that teachers who integrate computers are usually aware that one must allow students to learn and progress at their own rhythm and to challenge them with learning, behavioral, and social objectives that are appropriate to their individual ability.

Further evaluation of student achievement in math in that same population after three years of working on the computer, confirms the findings of previous studies [7]. It is clear that as far as progress in math in underprivileged populations is concerned, the effectiveness of the computer system is retained even after the novelty wears off and the system is no longer foreign to students.

\section{Comparing how male and female students use the computer in school}

This study also investigated if student gender was a factor that affected their experience in computerassisted learning. Previous studies that have examined correlation between student gender and achievement in computer-assisted learning in the case of struggling students indicate that boys benefit far more learning with the computer [13]. It was also found that boys have greater confidence than girls in their ability to reach achievements in the fields of computers and mathematics, even when there is no difference between the two genders in early computer experience. Other research suggests that girls have more negative attitudes than boys about using a computer and, already in elementary school, computers are perceived as a male domain. It was also found that boys participate more in computer-related activities by choice, demonstrate more interested in the subject both at home and at school, and tend to read information devoted to this domain. Boys use the computer more than girls, and reveal more positive attitudes about the use of the computer. Studies on the subject of computer literacy among both genders indicate that boys reveal a greater degree of knowledge and adeptness on the subject of computers. This gap in knowledge between the two genders can be explained by boys' greater experience in communicating with the computer [5 Sutton]. Interviews conducted with students on this topic reveal that girls tended to address the computer workspace whereas boys focused on the technology and techniques related to the computer. This difference in attitude can be explained by the boys' self-awareness of mastering the computer and also, as said, by the greater experience they have accumulated in this field. $[14,15]$.

It is worthy to note in this context that in schools where computer lessons are an integral part of the curriculum, especially in primary school, there was no difference found between the genders in the tendency to take part in activities that were computer related, in their positions regarding using the computer, or any anxieties related to it. 
Mores and Daiute [16] have claimed that, apparently, the investigators themselves were a cause of the bias against women and girls in the studies that involved the subject of computers and how the different genders use them. They claim that different methodological elements of research in studies that deal with the relationship between gender and computer use and between function in this area is biased from the outset, and this bias perpetuates the gender gap with respect to computers. To prove their claim, Mores and Daiute observed over a number of weeks the behavior of both genders in the computer environment. They found that the female attitude with respect to the computer was extremely positive: they were excited to use the computer and exhibited much confidence using it. In parallel, they carried out a study about attitudes using a questionnaire. The attitudes of the females, as reflected from the questionnaires, were completely different from the results obtained through observation.

\section{Method}

\subsection{Hypotheses}

Our main assumption is that teachers who implement alternative teaching methods in the classroom develop their students more than teachers who teach in the traditional, frontal method and thus tend to ignore student diversity. We thus compared student achievement in mathematics in computerassisted classes. Half the population was taught using the frontal method and half using alternative methods (small groups, more discussion, etc.). Student achievement was determined via the report of the school's computer system.

We developed four hypotheses:

I. Weak and average students instructed with alternative methods will show higher achievement than those instructed in the frontal method.

II. The gap between methods will increase with age.

III. High achievers will progress equally in both teaching methods.

IV. Significant differences will be found in achievement in mathematics between male and female students who are taught bydifferent teaching methods, since the girls will better express their ability in small groups and will tend to participate more actively in activities presented in this framework in which their chance to develop their mathematical thinking is greater.

The central variable in the study is the teaching method (frontal or alternative) used. Note that it is not entirely the presence or not of computers. Both groups used the computer as an aide for teaching math, but the alternative teachers used it more extensively.

\subsection{Participants}

The research population $(n=479)$ included both male and female students studying in two urban schools considered "underprivileged" by the Board of Education. They were enrolled in 3 classes each of grades 4, 5 and 6 in each of the schools (total: 18 classes and 18 teachers, see Table 1). Most of the teachers had at least 8 years teaching experience and were graduates of a teachers' seminary or degree programs. Nine teachers taught math using the frontal method and nine used the alternative method.

Table 1. Population, male and female students and teaching method.

\begin{tabular}{cccccc}
$\begin{array}{c}\text { Teaching } \\
\text { method }\end{array}$ & Frontal & \multicolumn{2}{c}{$\begin{array}{c}\text { Alter- } \\
\text { native }\end{array}$} & $\begin{array}{c}\text { Grade } \\
\text { total }\end{array}$ \\
\hline Gender & F & M & F & M & \\
\hline Grade 4 & 52 & 48 & 44 & 41 & 185 \\
Grade 5 & 34 & 36 & 36 & 46 & $\mathbf{1 5 2}$ \\
Grade 6 & 38 & 37 & 33 & 34 & $\mathbf{1 4 2}$ \\
\hline n & 124 & $\mathbf{1 2 1}$ & $\mathbf{1 1 3}$ & $\mathbf{1 2 1}$ & $\mathbf{4 7 9}$ \\
\hline
\end{tabular}

\subsection{Tools and process}

The level of mathematics instruction required for each class was defined by the teaching plan of the Ministry of Education (MoE). Identical textbooks were used in both schools. Math was taught for an identical amount of time (5 hours) per week: two 20minute sessions were computer assisted and student achievement data was documented by the computer.

All the teachers underwent identical coaching by the same supervisor concerning subjects to work on in the computer room and in class, were presented with comprehensive information regarding teaching attitudes and methods, and participated in teacher training conducted by MoE staff.

One MoE inspector supervised all the activity and supplied supporting information. Full reports were collected at the end of each month. Authorized observation of one entire lesson was conducted once for each class during the study, after which the teacher completed a questionnaire concerning teaching methods (in the class and in the school in general).

\subsection{Data collection}

Data concerning time organization, physical environment, educational activity, and teaching aids were documented on an observation sheet in order to identify those classes where alternative teaching was employed, that is to say personal instruction and 
small-group instruction were observed. Frontal teaching was defined as presentation and explanation of material without integrating individual or group work. Observers checked how much of the teaching was individual or group, to what extent students had opportunities to work independently and gain personal experience in the learning process, and to what extent learning materials were graded and varied. They also evaluated the atmosphere in the classroom and how the teacher worked with students and staff.

Questionnaires. Observation data was reinforced with teacher questionnaires, which comprised 59 Likert-type statements [ranked from 1 (not at all) to 5] that addressed teachers' openness to change and variation in teaching methods, and the use of computers in teaching and evaluation. The questionnaires were critiqued by experts before distribution. Analysis confirmed the division into frontal and alternative teaching groups established by observation, and showed the differences between the two methods to be meaningful and significant.

Data analysis. Hypotheses were tested using an analysis of covariance (ANCOVA), with statistic control of the independent variable: the number of lessons in which the student participated during the school year. We chose this method due to the differences in the number of computer sessions in the classes according to the teaching methods. After collecting data and before analysis, we compared the number of computer sessions held in the two types of classes. The difference was so significant [Grade 4: 94.7/56.4 hours (alternative/frontal); Grade 5: 106.7/57.6; Grade 6: 99.4/33.2] that we classed this data as a controlled variable.

Differential analyses tested the effect of the independent variables - method, age and gender - on the three dependent variables of progress. These analyses were conducted in groupings of method (2), gender (2), and age (3). Because of the complexity of the analysis, we separated the analysis by method and age from the analysis by method and gender.

Students were divided into weak-, average-, and strong-level groups. Chi-square tests were conducted to test differences in annual progress between the three levels of students according to two independent variables: teaching method and age. Differential analyses were not carried out on student levels due to this variable's dependence on computer scores.

Two years later, we obtained the average scores of the MoE's district 6th-grade mathematical achievement tests (for the students who had been in 4 th grade at the time of our study) three classes from each school.

\section{Results}

With respect to student level, we found that the higher the grade, the fewer the students who met grade level or above. Notwithstanding, all classes displayed a strengthening of level throughout the year, that is, there were fewer weak or average students at the end of the year than the number at the beginning.

Regarding our four hypotheses, we concluded the following:

Hypothesis I. Comparison of observed averages with corrected averages (had all the students participated in the same number of computer sessions) showed significant differences in progress in solving exercises $(f(1,459)=5.33, p=0.02)$. In fact, students who were taught in the frontal method demonstrated a decrease $(\mathrm{m}=-5.17)$ but alternative-method students an increase $(m=3.15)$. The differences with the computer were not significant at a level of $\mathrm{p}=0.05$, but were significant at $\mathrm{p}=0.08$ in favor of the alternative method $(\mathrm{f}(1,459)=2.94, \mathrm{p}=0.08)$. No difference was found in solving word problems.

Hypothesis II. We used differential analysis to compare the three dependent variables under the effects of class level and teaching method (the number of computer sessions was a controlled variable). This showed a significant interactive effect in progress for the computer only $(f(2,459)=16.7, p=0.000)$ and not for the other two variables. A post-hoc test to check interactive effect was significant in all class combinations. F-values for the differences between grades 5 and 6 were extremely high, and even more so between grades 4 and 6, indicating that the gap widens with age, favoring the alternative method. This corroborates our second hypothesis: the older the student, the greater his/her improvement. Figure 1 illustrates how the difference in achievement widens from 4th grade to 6th grade for the two methods.

Hypothesis III. Students in each class were categorized into three groups based on their relative computer levels at the beginning and end of the year:

initially weak, remained weak $(\mathrm{W}-\mathrm{W})$,

initially weak, progressed to average (W-M),

initially average, remained average (M-M),

initially average, progressed to strong (M-S),

strong throughout the year (S-S).

(Note: For the purpose of this study, one student who began strong and regressed to average is included in S-S; two students who began weak and progressed to strong are considered W-M.)

We checked this hypothesis with a chi-square test, using the five categories described above as variables (in frontal and alternative teaching). With the frontal method, $29 \%$ of the weak students began and ended the year (frontal teaching) as weak (i.e. $71 \%$ progressed). $18 \%$ of the average students progressed to strong (i.e. $82 \%$ remained average), and only $20.4 \%$ of strong maintained their standing. 


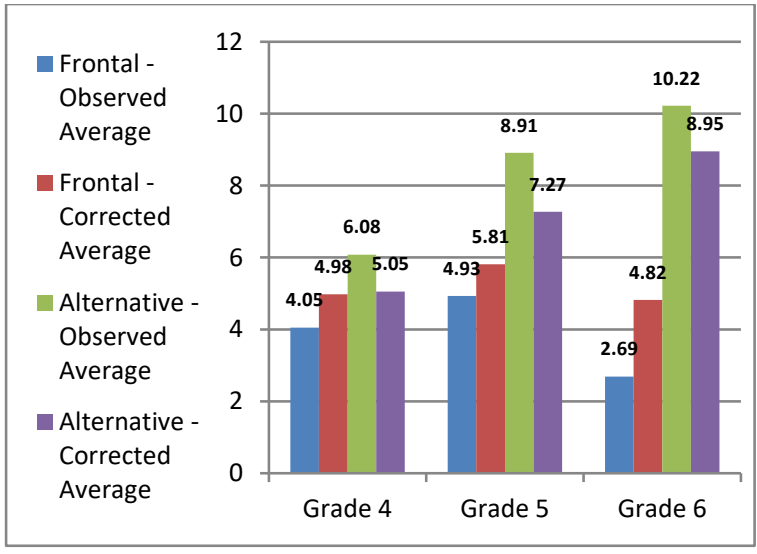

Figure 1. Average progress according to method and grade

By contrast, in the alternative classes, not one of the $5 \%$ who began weak remained so by the end of the year. Similarly, $35.2 \%$ of the average students progressed to strong, and the $49.3 \%$ of students who began as strong maintained their strong standing

Analysis of the distribution within the groups showed that with the alternative method, most of the students who began the year as average progressed to strong $(76.9 \%)$, while in the frontal method most average students remained average $(53.7 \%)$. Note that strong students at the beginning of the year maintained their strong standing, regardless of the method of teaching.

The most striking finding is that most of the students in the frontal method remained in their original level, while most students in the alternative method progressed to a higher level. This corroborates the third hypothesis.

Two-year follow-up. MoE test scores showed that two years later, the students in the alternative method retained their lead over those from the frontal method. The average scores of the three classes of 6 th graders who had undergone frontal instruction (they had been in 4th grade during the study) were 61.7, 61.8, and 62.5. This is substantially lower than the scores of those who had studied in the alternative method (68, 77.4, 84.3).

In addition, the percentage of failures in the district test was compared with the percentage of failures collated from the computer results two years earlier, for each of the teaching methods. Of the frontalmethod students, $32 \%$ failed in the computer and $39 \%$ failed the district test, while only $14 \%$ of alternative students failed in the computer and $16 \%$ failed the district test. These results of the district test echo the computer results of two years earlier, even though different instruments were used.

The significant positive effect that alternative teaching has on student achievement in mathematics over the frontal method was preserved even when the number of computer classes in which the student participated during the school year served as a controlled variable. Significant differences were found between the two teaching methods regarding progress on the computer and progress in solving exercises.

Furthermore, we saw a correlation between teaching method and age: the older the students, the greater the gap in achievement on the computer. This gap was sustained for at least two years, as shown by the results of MoE district test, where the success rate of students who studied with computer-assisted learning and alternative classroom teaching methods was $84 \%$, compared to $61 \%$ for those who did not.

Hypothesis IV. The fourth hypothesis was that a significant difference would be found in the mathematical achievements between male and female students who learn in each of the ways. The hypothesis was tested with the the number of computer lessons that the student took part in as the statistically controlled variable. The independent variables were teaching method (alternative, frontal) and gender (male, female). The results of the study is presented in Table 2, which displays the results of a co-variance analysis.

Table 2. Difference in scores of students' achievement based on teaching method and gender

- progress scores, adjusted scores, standard deviation and $f$ values.

\begin{tabular}{|c|c|c|c|c|c|}
\hline $\begin{array}{l}\text { Teaching } \\
\text { method }\end{array}$ & \multicolumn{2}{|c|}{ Frontal } & \multicolumn{2}{|c|}{ Alternative } & \multirow{2}{*}{$\begin{array}{c}\mathrm{f}- \\
\text { values }\end{array}$} \\
\hline Gender & $\mathrm{M}$ & $\mathrm{F}$ & $\mathrm{M}$ & $\mathrm{F}$ & \\
\hline $\begin{array}{l}\text { Progress } \\
\text { on the } \\
\text { computer }\end{array}$ & $\begin{array}{r}3.79 \\
(2.39)\end{array}$ & $\begin{array}{r}3.98 \\
(2.07)\end{array}$ & $\begin{array}{r}8.38 \\
(4.37)\end{array}$ & $\begin{array}{r}8.26 \\
(3.96)\end{array}$ & \multirow[t]{2}{*}{.05} \\
\hline $\begin{array}{l}\text { Adjusted } \\
\text { mean }\end{array}$ & 5.43 & 5.47 & 6.81 & 6.69 & \\
\hline $\begin{array}{l}\text { Progress } \\
\text { in solving } \\
\text { problems }\end{array}$ & $\begin{array}{r}-6.48 \\
(23.48)\end{array}$ & $\begin{array}{r}-3.89 \\
(16.18)\end{array}$ & $\begin{array}{r}3.80 \\
(19.07)\end{array}$ & $\begin{array}{r}2.45 \\
(14.34)\end{array}$ & \multirow[t]{2}{*}{1.50} \\
\hline $\begin{array}{l}\text { Adjusted } \\
\text { mean }\end{array}$ & -2.28 & 2.79 & 2.66 & 1.32 & \\
\hline $\begin{array}{l}\text { Progress } \\
\text { in solving } \\
\text { word } \\
\text { problems }\end{array}$ & $\begin{array}{r}3.42 \\
(3.18)\end{array}$ & $\begin{array}{r}3.16 \\
(3.40)\end{array}$ & $\begin{array}{r}6.86 \\
(4.70)\end{array}$ & $\begin{array}{r}7.81 \\
(4.95)\end{array}$ & \multirow[t]{2}{*}{$* 3.60$} \\
\hline $\begin{array}{l}\text { Adjusted } \\
\text { mean }\end{array}$ & 5.60 & 5.15 & 4.77 & 5.73 & \\
\hline
\end{tabular}

Observation of Table 2 indicates that there is a clear interactive effect between teaching method and gender with respect progress in computer level or progress in solving problems. Female students who learned with the alternative method progressed in the area of solving word problems more than boys who 
learned in the same method. In fact, their progress in this area was greater than in any other variable tested between the boys and girls who learned with alternative method. The fourth hypothesis was therefore confirmed, although only partially.

Within the framework of the statistical analysis, we also tested for a triple interaction (teaching method, age, gender) but found sucn an interaction to be not statistically significant.

However, we did find a correlation between teaching method and age: the higher the age of the students, the greater was the gap between achievement in computer level, with an advantage to students taught with the alternative method in their homeroom.

\section{Discussion}

The hypothesis that there is a connection between the teaching method used in the classes and student performance in mathematics has a solid basis [see for example, $[12,13,14,15]$, and it is fairly established that diversified teaching methods that veer from the traditional frontal method can activate and involve all students in the heterogeneous class and allow the introduction of teaching technologies tailored to the needs of students.

It should be noted that, in all cases, the number of computer classes attended by each student was taken into account. This variable was statistically controlled in the covariance analysis. Advanced comparisons showed that, on the average, students in frontal classrooms attended about half the number of computer classes than those in alternative classrooms. In any case, however, the findings show a gap in achievement favoring students who studied with the alternative teaching method, regardless of the number of computer classes in which the students participated.

The study also shows that the method affects different age groups (grades 4-6) differently, that is, the gap in achievement increases with age. It appears that students studying in the alternative method improve over the years while students studying in the frontal method weaken over the years.

The study also compared the progress of various levels of students (weak, average, strong) within each class based on the teaching method and found that a significant percentage of weak and average students who studied in the alternative teaching method advanced to a higher level within their class. In contrast, most of the frontal-method students remained at the level in which they began the academic year. In other words, weak and average students in the alternative teaching method are able to reduce the initial gap between them and their classmates, while students in the frontal method fail to close the gap and are left behind.

\subsection{Reasons underlying the different results}

Although the basic conditions for teaching mathematics were similar in the two schools, the achievement levels in the alternative method were higher. This raises the question: What takes place in the classroom in each method that affects achievement as observed?

One aspect is how the teachers relate to their students. Teachers who practice alternate methods relate to their students individually and match teaching method and study material to each one's unique needs and personal capabilities. Students take responsibility for their own learning and progress at their own pace and ability. Conversely, teachers using the frontal method consider the class to be a single unit. The method is suitable for the average student: however, strong students quickly lose interest while weak students are unable to follow the subject matter, do not fully participate, and fall by the wayside.

Another aspect concerns the connection between classroom teaching and learning in the computer room. Computer-assisted learning is individual learning. The alternative method suits the computer room and this affects classroom learning since difficulties that arise in the computer room can be later resolved by the teacher in the classroom and vice versa. This ensures continuity between the classroom and the computer room and increased effectiveness.

By contrast, frontal teaching is disconnected from the learning process in the computer room. Difficulties that arise during the work in the computer room are not resolved in the classroom, therefore students experiencing difficulties are unable to keep up in the classroom nor progress in the computer room; their loss is double. Teachers that use frontal teaching ignore any diversity revealed in the computer room, do not exploit the possibilities offered by the computer, and continue to teach for the average student, resulting, again, in bored high-achievers and confused weak students.

Furthermore, teachers who use alternative teaching consider computer learning to be integral, whereas frontal teachers do not attach importance to the computer's impact on the learning process and miss out on the computer's huge potential for learning.

In this context, it is worth noting that, over time, a school develops a teaching and learning culture that draws on its prevailing educational approaches and becomes integrated into its ethos $[17,18]$. This can explain the differences that occur between schools despite equal conditions in the learning environment. Schools that adhere to frontal teaching methods are less likely to adopt alternate tools - guidance, training, appropriate textbooks and various teaching aids tailored to the needs of the students. 


\subsection{Differences in student achievement}

The processes that students are exposed to in each of the teaching methods are what underlie the disparity in achievement. In the alternative method, the student is the heart of the learning process, takes responsibility, and is actively involved. They receive appropriate assistance in the classroom in response to difficulties they encounter in the computer room and at a level consistent with their personal ability. When they return to the computer room, they are in control of the material and can progress. Students in the frontal method do not receive adequate response to the problems they encounter. The learning process from the computer room has no continuation, and in the absence of support and reinforcement, the process stops and progress is arrested.

These findings corroborate the findings of Hativa $[19,20]$, according to which computer-assisted learning contributes to an increase in the gap between weak and advanced students and promotes good students in disadvantaged schools. In fact, it seems that good students do not need much help from the teacher; their natural curiosity leads to progress regardless of how they learn. Weak students, however, need personalized, focused assistance from the teacher. Because they do not receive this assistance in the frontal teaching method, their progress is halted. However, in the alternative method, they receive the personalized assistance to allow them to progress according to their ability.

Word problems. While the study found gaps in student achievement (based on teaching method) with respect to the indices of computer work and solving numerical exercises, there was no difference of achievements with respect to word problems. A possible explanation lies in the structure of the computer-assisted math curriculum. The computer presents a fixed number of word problems with a defined hierarchy. Questions in a particular topic are based on a fixed text with numbers that change from question to question. Progress is contingent on correctly solving the earlier questions in the sequence. The questions are ranked sequentially from second grade to eighth grade.

During computer practice, students are introduced to ten problems. The student must correctly solve at least six questions on the first try to move to a higher level; otherwise, the computer displays questions of similar structure with different numbers. In the second round, the requirements diminish and the threshold for success is lower, but in any case, the student must obtain the required level of success for ten word problems to advance to a higher practice level. In the other areas, the computer presents between five to ten exercises only, although the student must achieve the required level of success to advance to a higher level. However, because of the different format, to advance a level in word problems, students must participate in a greater number of classes than required for the other areas. Thus, the effect of the number of computer classes in which the student participated on the progress in word problems is clear.

In this connection, one should note that the method for word problems in the computer-assisted math curriculum has not yet been finalized because of the complexity involved in ranking the difficulty of word problems, which requires, besides the mathematical sophistication of the problem, evaluation of the content regarding semantic, linguistic, logical, and other elements.

\subsection{Differences in achievement in mathematics based on teaching method and gender}

Within the framework of this study, the differences in achievements in mathematics between male and female students were studied as a factor of the teaching method used. It was found that in the case of solving word problems, girls who were taught using the alternative teaching method achieved higher scores than boys taught using the same method. The findings listed above are the basis for the discussion below, which focuses on the differences between male and female with respect to different teaching methods, which is one of the more interesting findings in this study. This finding is similar to that reported by Hertz-Lazarowitz, Calderon and Ivory, who found that teaching reading and writing in small learning groups positively affected mainly girl students, who did not only progress faster in the subject of Hebrew, but also in mathematics and sciences, and reached greater achievements than boys taught in the same method or that girls taught using the frontal method. It seems that in small groups, girls feel more selfconfident and are not deterred from actively participating in the learning event. They talk more in this framework and ask more questions, and thus they learn and progress more. On the other hand, in classes were the frontal method was used, the sampling tended to favor the boys [15].

The study also suggests that the alternative teaching method offers an advantage to weak or average students, while the frontal method does not encourage their advancement: weak students who are taught in this method remain weak and average students remain average. It seems that only advanced students retain their high rankings no matter what the teaching method. This can be explained by the fact that the alternative method retains a sequential between the teaching process in the classroom and the teaching activities in the computer room, whereas with the frontal method, there is a disconnection between what goes on in the classroom and the computer room. 


\section{Conclusions}

The study shows that the alternative method of teaching promotes improvement in weaker and average students whereas with the frontal method the weak and average students remain weak and average, respectively. This gap continues over the years. This is explained by the fact that alternative teaching maintains continuity between the classroom learning process and learning activity in the computer room whereas frontal teaching does not. The findings indicate the importance of integrating flexible teaching styles into mathematics teaching.

\section{References}

[1] Harari, H. \& the Supreme Committee for Education in Technology and Sciences (1992). "Diyun benosse dokh va'adat Harari" [Discussion on the Harari committee]. Tel Aviv, Israel: Ort. [In Hebrew].

[2] Reznitskaya, A., \& Gregory, M. (2013). "Student thought and classroom language: Examining the mechanisms of change in dialogic teaching”, Educational Psychologist, 48(2), 114-133. doi:10.1080/00461520.2013.775898

[3] Salomon, G. (2002). "Technology and pedagogy: Why don't we see the promised revolution?", Educational Technology, 42(2), 71-75.

[4] Salomon, G. \& Perkins, D.N. (2005). "Do technologies make us smarter? Intellectual amplification with, of and through technology". In D. D. Preiss \& R. Sternberg (Eds.). Intelligence andTtechnology. (pp. 71-86). Mahwah, NJ: LEA.

[5] Sutton, R.E. (1991), "Equity and computers in the school: A decade of research", Review of Educational Research, 61(4) 475-503.

[6] Thorvaldsen, S., Vavik, L \& Salomon, G. (2012). "The use of ICT tools in Mathematics: A case-control study of best practice in $9^{\text {th }}$ grade classrooms", Scandinavian Journal of Educational Research, 56(2), 213-228.

[7] Osin, 1., Nesher, P. \& Ram, J. (1994). "Do the rich become richer and the poor poorer? A longitudinal analysis of pupil achievement and progress in elementary schools using computer assisted instruction", International Journal of Educational Research, 21(1), 53-64,.

[8] Osin, L. (1984), "TOAM: C.A.I. on a national scale". In Proceedings of the 4th Jerusalem Conference on Information Technology (pp. 418-424). Silver Spring, MD: IEEE Computer Society.

[9] Osin, L. \& Nesher, P. (1989) "Comparison of student performance in Arithmetic exercises: TOAM vs. paper and pencil testing. International, Journal of Man-Machine Studies, 31, 293-313.
[10] Hativa, N., Shapira, R. \& Navon, D. (1990) "Computer-managed practice effects on instructional methods and on teacher adoption", Teaching and Teacher Education, 6(1), 55-68.

[11] Mevarech, Z. R., \& Kramarski, B. (1997). "Improve: A multidimensional method for teaching mathematics in heterogeneous classrooms", American Educational Research Journal, 34(2), 365-394.

https://doi.org/10.3102/00028312034002365

[12] Swan, K., Guerrero, F., Mitrani, M. \& Schoener, J. (1990). "Honing in on the target: Who among the educationally disadvantaged benefits most from what CBI?", Journal of Research on Computing in Education, 22(4), 381-403.

[13] Tiedemann, J. (2000). "Gender-related beliefs of teachers in elementary school Mathematics", Educational Studies in Mathematics 41( 2). 191-206.

[14] Sefer, M., Hertz-Lazarowitz, R., \& Ben-Tzvi-Meir, S. (1993), "Classifying girls and boys as outstanding students as viewed by their peers", Psychologiya (3)2, 153-165. [Hebrew]

[15] Ben Tsvi-Mayer, S., Hertz-Lazarowitz, R., \& Safir, M. (1993). "Teachers' selections of boys and girls as prominent pupils." In: Y. Azmon and D.N. Izraeli (eds.) Women in Israel: Studies of Israeli Society. Volume VI, Transaction Publishers, New Brunswick (USA) and London (UK), 379394.

[16] Mores, F.K. \& Daiute, C. (1992). "I LIKE computers vs. I LIKERT computers: Rethinking methods for assessing the gender gap in computing." Paper presented at the annual conference of the Americaln Educational Research Association, San Francisco. ERIC Document No. 349939.

[17] Tinajero, J., Calderon, E. M., \& Hertz-Lazarowitz, R. (1993). "Cooperative learning strategies: Bilingual classroom application." In: J.V. Tinajero \& A.F. Ada (Eds.). The Power of Two Languages: Literacy and Biliteracy for Spanish Speaking Students. New York: McMillan/McGraw Hill, pp. 241254.

[18] Järvenoja, H., \& Järvelä, S. (2009). "Emotion control in collaborative learning situations. Do students regulate emotions evoked by social challenges?", British Journal of Educational Psychology, 79(3), 463-481.

[19] Hacohen, A., Osin, L., Ginosar, Z., Zabar, N., \& Sharon, D. (1992). "Hahinukh shnot ha'alpayim [Education in the twentieth century]", Ma'aseh Hoshev, 19, 36-23. [In Hebrew]

[20] Bielaczyc, K. (2006). "Designing social infrastructure: Critical issues in creating learning environments with technology", Journal of the Learning Sciences, 15(3), 301329. 